\title{
Pulmonary Resection for Metastasis of Hepatocellular Carcinoma Recurring After Liver Transplant: An Italian Multicenter Experience
}

\section{OPEN ACCESS}

Edited by:

Giulia Maria Stella,

San Matteo Hospital Foundation (IRCCS), Italy

Reviewed by: Luca Rinaldi,

University of Campania Luigi Vanvitelli, Italy

Pietro Rinaldi,

San Matteo Hospital Foundation (IRCCS), Italy

Qiang Pu,

Sichuan University, China

*Correspondence:

Massimo lavarone

massimo.iavarone@gmail.com

Specialty section:

This article was submitted to

Molecular and Cellular Oncology,

a section of the journal

Frontiers in Oncology

Received: 19 September 2019

Accepted: 04 March 2020

Published: 15 April 2020

Citation:

Invenizzi F, lavarone M, Donato MF, Mazzucco A, Torre M, Conforti S, Rimessi A, Zavaglia C, Schiavon M, Comacchio G, Rea F, Boetto R, Cillo U, Dondossola D, De Carlis L,

Lampertico P, Nosotti M and Mendogni P (2020) Pulmonary

Resection for Metastasis of Hepatocellular Carcinoma Recurring After Liver Transplant: An Italian

Multicenter Experience.

Front. Oncol. 10:381

doi: 10.3389/fonc.2020.00381

\begin{abstract}
Federica Invenizzi ${ }^{1}$, Massimo lavarone ${ }^{1 *}$, Maria Francesca Donato ${ }^{1}$, Alessandra Mazzucco ${ }^{2}$, Massimo Torre ${ }^{3}$, Serena Conforti ${ }^{3}$, Arianna Rimessi ${ }^{3}$, Claudio Zavaglia ${ }^{4}$, Marco Schiavon $^{5}$, Giovanni Comacchio ${ }^{5}$, Federico Rea ${ }^{5}$, Riccardo Boetto ${ }^{6}$, Umberto Cillo ${ }^{6}$, Daniele Dondossola ${ }^{7}$, Luciano De Carlis ${ }^{8}$, Pietro Lampertico ${ }^{1,9}$, Mario Nosotti ${ }^{2,10}$ and Paolo Mendogni ${ }^{2}$
\end{abstract}

${ }^{1}$ Division of Gastroenterology and Hepatology, CRC "A. M. and A. Migliavacca" Center for Liver Disease, Fondazione IRCCS Cà Granda Ospedale Maggiore Policlinico, Università degli Studi di Milano, Milan, Italy, ${ }^{2}$ Thoracic Surgery and Lung Transplant Unit, Fondazione IRCCS Ca' Granda Ospedale Maggiore Policlinico, Milan, Italy, ${ }^{3}$ Thoracic Surgery Unit, Ospedale Niguarda, Milan, Italy, ${ }^{4}$ Hepatology and Gastroenterology Department, Niguarda Ca' Granda Hospital, Milan, Italy, ${ }^{5}$ Department of Cardiac, Thoracic, Vascular Sciences and Public Health, Padua University Hospital, Padua, Italy, ${ }^{6}$ Department of Surgery, Oncology and Gastroenterology, Hepatobiliary Surgery and Liver Transplantation, Padua University Hospital, Padua, Italy, ${ }^{7}$ HBP Surgery and Liver Transplantation Unit, Fondazione IRCCS Ca' Granda Maggiore Hospital, University of Milan, Milan, Italy, ${ }^{8}$ Department of General Surgery and Transplantation, Niguarda Ca' Granda Hospital, Milan, Italy, ${ }^{9}$ University of Milan, Milan, Italy, ${ }^{10}$ Department of Pathophysiology and Transplantation, Università degli Studi di Milano, Milan, Italy

Background and aim: Liver transplantation (LT) is a validated treatment for hepatocellular carcinoma (HCC). HCC recurrence occurred between 8 and 20\% of patients and lung is the most frequent site. Pulmonary metastases resection (PMR) prolongs survival, however in LT-setting the impact on survival is unclear. To give new lights on this issue, we report the experience of three Italian LT Centers.

Methods: All consecutive HCC transplanted patients in three Italian LT Centers, who developed pulmonary metastasis from HCC (PM-HCC), as first metastasis, from 2008 to 2018, were included whenever treated with PMR.

Results: Twenty-five patients were enrolled (median age 58 yrs, 84\% male, 3\% cirrhotics). HCC recurred after 34 months (9-306) since LT and PMR was performed after 2.4 months (0-43.1). A total of 28 PMR (19 single resections; 9 multiple resections; 16 right; 2 left) have been performed on 24 patients while in one case percutaneous microwave ablation (MWA) was preferred. Four patients have been re-operated due to pulmonary HCC-recurrence after surgery. The majority of surgical resection type was wedge resection (26, 89\%). Surgical access was: video-assisted thoracic surgery (VATS) in 17 cases (59\%); thoracotomy in 11 (38\%); MWA in 1 (3\%). The 48\% of nodule was in right lower lobe. Perioperative in-hospital mortality and 30 days mortality were nil; median surgical time 90 min (50-365); median post-operative overall stay 5 days (2-11). Post-operative ICU treatment was necessary in 1 case (3\%) for 3 days; blood transfusions in 2 cases (7\%). Overall, 5 complications (2 bleeding; 1 $\mathrm{AKI} ; 1$ major cardiac; 1 wound dehiscence) occurred, with an overall complications rate of $23 \%$. Eight (32\%) patients died during a follow-up after HCC recurrence of 32 months (7-213): 7 for HCC progression, 1 for severe liver failure due to chronic 
rejection. The 1 and 5 year cumulative probability of OS from recurrence were 100 and $43 \%(95 \% \mathrm{Cl} 12-74)$, respectively, with a median OS of 51 months $(95 \% \mathrm{Cl} 24-78)$.

Conclusion: Selected patients with isolated pulmonary HCC-recurrence after LT and with preserved hepatic function showed that a pulmonary metastasectomy could be efficacious in managing a PM-HCC and could give an opportunity for long-term survival.

Keywords: hepatocellular carcinoma, liver transplantation, recurrence, pulmonary metastases, pulmonary resection

\section{INTRODUCTION}

Liver transplantation (LT) is a validated treatment for hepatocellular carcinoma (HCC) $(1,2)$. The risk of HCC recurrence varies between 8 and $20 \%$ depending on pretransplant-variables such as the tumor burden and the alpha-fetoprotein (AFP) level (3-7). Moreover, HCC recurrence after LT is an accepted and not exceptional clinical challenge (8). In fact, it reduces LT curative intention, being the survival reduced as low as 3.3 months when only best supportive care is offered (9). Surveillance and administration of HCC recurrence after LT is exciting and complicated. More frequently, recurrence occurs within the first 2 years (10), although cases of very late recurrence after a 10 year period have been reported $(11,12)$.

Regarding the sites of HCC recurrence, the first revelation is more frequently extra-hepatic (as high as 71\%), followed by intra-hepatic and simultaneously intra- and extra-hepatic (13). In addition, intra- or extrahepatic recurrence, or the combination of both, did not result in different outcomes. Among the extrahepatic sites of recurrence, the lung is the most frequent metastatic site (5). Pulmonary metastases resection (PMR) for HCC improves survival in patients treated by liver resection or ablative procedures (14). Although some investigators recommend PMR also for HCC recurrence after LT $(15,16)$, in this setting the impact on survival is unclear and today pulmonary metastases for HCC (PM-HCC) after LT are infrequently resected due to their multiplicity and multiorgan involvement.

To give new lights on this issue, we report the experience of three Italian LT Centers regarding pulmonary metastasectomy for HCC after LT in terms of safety, complication, risk of recurrence, and survival.

\section{PATIENTS AND METHODS}

\section{Study Design, Patients, and Endpoints}

This is a retrospective evaluation of a cohort of prospectively enrolled patients in three different Liver Transplant Centers in Italy (two in Milan and one in Padua). All consecutive HCC transplanted patients, who developed PM-HCC, as first metastasis, from 2008 to 2018 were included in this study whenever treated with lung surgery resection. The database was locked in June 2019. Baseline corresponded to first HCC recurrence after LT with lung metastases. Each patient signed a written informed consent in conformity with the ethic committee and the ethical guidelines of the 1975 Declaration of Helsinki, as updated in 2004.

A contrast-enhanced thoraco-abdominal computed tomography (CT)-scan was performed every 6 months for the first 5 years, and then annually in all HCC transplanted patients. Serum AFP was quantified every 3 months during the first year and every 6 months thereafter. In case of suspected HCC recurrence, biopsy was performed when the site of recurrence is reachable. Otherwise, the diagnosis was obtained by imaging associated with AFP levels increase. Once the diagnosis was obtained, surgery treatment was performed whenever judged appropriate, with a curative or palliative intent. For the analysis, treatments were considered with a curative intent if the removal of the neoplastic lesion led the patient HCC-free.

Once the diagnosis was obtained, in one of the three centers sorafenib was started as soon as became available and its use safe (i.e., after healing of surgical wound in surgical patients) and mammalian target of rapamycin inhibitor (mTORi)based immunosuppression regimen (sirolimus or everolimus) was considered.

The following data were collected: demographics and pre-LT history, native liver histological tumor staging, immunosuppressive regimens, time, characteristics and treatments of HCC recurrence, surgery procedures, and complications.

The primary endpoint was safety of surgery on lung metastasis in HCC recurrent patients after LT. Secondary endpoints were feasibility of surgery in these patients, recurrence after the first surgical treatment and survival.

Surgery safety was assessed with evaluations of multiple parameters: perioperative in-hospital mortality (considered as death for any causes during post-operative in-hospital course), 30 days mortality (considered as death for any causes within 30 days after thoracic surgery), surgical skin-toskin time, post-operative hospital stay, need of post-operative intensive care unit (ICU), blood transfusions, readmission rate, post-operative complications. We considered as complication any of the following: bleeding, pneumonia, major cardiac complications (atrial fibrillation or acute myocardial ischemia), persistent air leak $>7$ days, wound infection or dehiscence, acute kidney injury (AKI). A CT-scan every 2 months after surgery and during follow-up was used to assess tumor response, according to modified Response Evaluation Criteria in Solid Tumors (RECIST) criteria (17). Time to radiological progression was defined as the time elapsed from baseline to disease progression according to modified 
RECIST criteria for HCC. Overall survival (OS) was measured from the date of first surgical intervention until the date of death from any cause or date of the last visit. Baseline variables were also analyzed in order to identify predictors of OS.

\section{Surgery}

Patients with suspected or diagnosed thoracic metastasis from HCC have been referred to thoracic surgery department. Firstly, all referred patients were screened and judged suitable or unsuitable for metastasectomy from surgical anatomical point of view. Considering the metastatic nature of the thoracic nodules, the intervention proposed was a minimally invasive lung-sparing resection, whenever possible. If positively judged for surgery, patients were functionally evaluated by cardio-pulmonary tests and, finally an anathesiological risk was formulated, according to the American Society of Anesthesiologists (ASA) physical status classification system. The intraoperative and post-operative management was carried out in a standard way.

\section{Statistical Analysis}

We used standard statistics (median and range for continuous variables, percentage for categorical variables) to describe baseline series characteristics and safety data. Survival time was computed as the interval between first HCC recurrence and death (survival after recurrence). Survival time was censored at the date of last contact in living patients. Survival curves were estimated with the non-parametric Kaplan-Meier method. Calculations were done using SPSS Statistics Program.

\section{RESULTS}

Twenty-five patients were enrolled. Patients' baseline characteristics are shown in Table 1. HCC recurred after a median of 33.6 months (8.9-306.4) since LT. PM-HCC treatment was performed after a median of 2.4 months (043.1) following HCC recurrence. A total of 28 PMR (19 single resections; 9 multiple resections; 16 right; 2 left) have been performed on the 24 enrolled patients. In additional patient, transthoracic percutaneous microwave thermoablation (MWA) was preferred, due to the high risk for surgery. Four patients have been re-operated due to pulmonary HCC-recurrence after the first PMR. The majority of surgical resection type was wedge resection ( $n=26,89.2 \%$ ), while only one segmentectomy and one lobectomy were performed. The surgical access was as follows: video-assisted thoracic surgery (VATS) in 17 cases (58.6\%); thoracotomy (11 cases, 37.9\%); MWA (1 case, 3.4\%). None conversion from VATS to thoracotomy was needed. The presence of pleural adhesions was observed in 7 cases $(24.1 \%)$. The average of nodules treated per procedure was $1.5(1-4)$. The majority of nodule treated was in right lower lobe (12), followed by left lower lobe (7), left upper lobe (6), right upper lobe (4), and right middle lobe (3). In Table 2 per-patient's characteristics were presented.
TABLE 1 | Baseline features of the 25 patients enrolled in the study.

\begin{tabular}{|c|c|}
\hline Features & Overall $(n=25)$ \\
\hline Age, years* & $58(41-73)$ \\
\hline Male, N. & $21(84 \%)$ \\
\hline Smoke, N. & $8(32 \%)$ \\
\hline COPD, N. & $5(20 \%)$ \\
\hline FEV1, \% of predicted* & $91(76.1-124)$ \\
\hline CAD, $N$. & 0 \\
\hline Diabetes, N. & $2(8 \%)$ \\
\hline $\mathrm{BMI}, \mathrm{kg} / \mathrm{m}^{2 \star}$ & 27 (19-30) \\
\hline Anticoagulant or antiplatelet drugs, N. & $6(24 \%)$ \\
\hline Cirrhosis, N. & $3(12 \%)$ \\
\hline \multicolumn{2}{|l|}{ Liver disease etiology, N. } \\
\hline $\mathrm{HCV}$ & $13(52 \%)$ \\
\hline HBV & $6(24 \%)$ \\
\hline Other etiologies & $6(24 \%)$ \\
\hline \multicolumn{2}{|l|}{ Native liver histology, N. } \\
\hline Milan-in & $12(48 \%)$ \\
\hline Microvascular invasion & $11(44 \%)$ \\
\hline Edmonson grade 3 or 4 & $9(36 \%)$ \\
\hline HCC recurrence time, months ${ }^{*}$ & $34(9-306)$ \\
\hline \multicolumn{2}{|l|}{ HCC recurrence pattern, $\mathrm{N}$. } \\
\hline Liver only & 0 \\
\hline Intra and extra-hepatic & 0 \\
\hline Extra-hepatic only & 25 (100\%) \\
\hline AFP levels, ng/mL* & $7(1-85)$ \\
\hline \multicolumn{2}{|l|}{ Immunosoppressive regimen, $\mathrm{N}$. } \\
\hline $\mathrm{CNi}+\mathrm{mTORi}$ & 4 (16\%) \\
\hline mTORi & 3 (12\%) \\
\hline $\mathrm{CNi}$ & 11 (44\%) \\
\hline $\mathrm{CNi}+\mathrm{MMF}$ & 7 (28\%) \\
\hline
\end{tabular}

${ }^{\star}$ Median (range); COPD, chronic obstructive pulmonary disease; FEV1, forced expiratory volume at 1s; CAD, coronary artery disease; BMI, body mass index, $\mathrm{HCV}$, hepatitis C virus; HBV, hepatitis B virus; HCC, hepatocellular carcinoma; AFP, alphafetoprotein; CNi, calcineurine inhibitor; $m$ TORi, mammalian target of rapamycin inhibitor; MMF, mycofenolate.

\section{Safety Analysis}

Perioperative in-hospital mortality and 30 days mortality were nil. Median surgical time (skin-to-skin) was $90 \mathrm{~min}$ (range 50365); median post-operative overall stay was 5 days (range 2-11). Post-operative ICU treatment was necessary in 1 case only (3.4\%), for 3 days. Blood transfusions were necessary in 2 cases $(6.9 \%)$. Readmission was required in 1 case $(3.4 \%)$. A total of 5 complications ( 2 bleeding; 1 AKI; 1 major cardiac; 1 wound dehiscence) were observed, with an overall complications occurrence of $22.7 \%$ (detailed in Table 2).

\section{Effectiveness and Survival}

The median follow-up after HCC recurrence was 32.5 months (7.4-213.0). Eight (32\%) patients died: 7 for HCC progression, 1 patient for severe liver failure due to chronic rejection. The 1-, 3 -, and 5 year cumulative probability of OS from recurrence were $100,66 \%$ (95\%IC 44-88) and 43\% (95\%CI 12-74), respectively, with a median OS of 51 months (95\%CI 24-78) (Figure 1). 
TABLE 2 | Individual surgery details and follow-up of the 25 patients enrolled in the study.

\begin{tabular}{|c|c|c|c|c|c|c|c|c|c|c|c|c|c|c|c|c|}
\hline Patients & Gender, age (years) & $\begin{array}{l}\text { Time to recurrence } \\
\text { from OLT (months) }\end{array}$ & $\begin{array}{l}\text { Nodules: number/ } \\
\text { size (mm) }\end{array}$ & PET scan & Resection & Lobe & $\begin{array}{l}\text { Surgical } \\
\text { access }\end{array}$ & ICU & $\begin{array}{l}\text { Blood } \\
\text { trasfusion }\end{array}$ & $\begin{array}{l}\text { Surgery } \\
\text { complications, } \\
\text { type }\end{array}$ & $\begin{array}{l}\text { HCC recurrence } \\
\text { after surgery }\end{array}$ & $\begin{array}{l}\text { Time of recurrence } \\
\text { from surgery } \\
\text { (months) }\end{array}$ & $\begin{array}{l}\text { Site of } \\
\text { recurrence } \\
\text { after surgery }\end{array}$ & $\begin{array}{l}\text { Polmonary } \\
\text { surgery } \\
\text { for recurrence }\end{array}$ & $\begin{array}{l}\text { Follow-up } \\
\text { (months) }\end{array}$ & Dead \\
\hline$\# 1$ & Male, 62 & 92 & $1 / 18$ & Pos & WEDGE & LUL & VATS & No & No & No & Yes & 8.7 & Abdomen & No & 50 & No \\
\hline \#2 & Male, 57 & 57 & $1 / \mathrm{NA}$ & NA & MWA & LUL & VATS & No & No & No & ** & NA & NA & NA & 39 & Yes \\
\hline \#3 & Male, 58 & 13 & $1 / 13$ & Neg & WEDGE & RLL & VATS & No & No & No & Yes & 4.1 & Lung & No & 97 & No \\
\hline \#4 & Female, 60 & 34 & $1 / \mathrm{NA}$ & Pos & WEDGE & RUL & VATS & No & No & $\begin{array}{l}\text { Yes, wound } \\
\text { infection/dehiscence }\end{array}$ & No & NA & NA & NA & 16 & No \\
\hline \#5 & Male, 61 & 18 & $1 / 12$ & Neg & WEDGE & LLL & VATS & No & No & No & $*$ & NA & NA & NA & 26 & Yes \\
\hline \#6 & Male, 58 & 25 & $1 / 5$ & Neg & WEDGE & RLL & VATS & No & No & No & Yes & 20.9 & Lung & Yes & 39 & Yes \\
\hline$\# 7$ & Male, 41 & 9 & $3 / \mathrm{NA}$ & NA & WEDGE & $\begin{array}{l}\text { RLL, } \\
\text { RUL }\end{array}$ & Thoracotomy & No & Yes & Yes, haemothorax & Yes & 9.2 & Multifocal & No & 31 & Yes \\
\hline \#8 & Male, 51 & 13 & $1 / 17$ & Neg & WEDGE & LUL & VATS & No & No & No & Yes & 16.3 & Liver & No & 29 & Yes \\
\hline \#9 & Male, 53 & 15 & $1 / 4$ & Pos & WEDGE & RUL & Thoracotomy & No & No & No & No & NA & NA & NA & 23 & No \\
\hline$\# 10$ & Male, 60 & 9 & $2 / 8$ & NA & WEDGE & ŁLL. & VATS & No & No & No & Yes & 5.3 & Bone & No & 7 & No \\
\hline \#11 & Female, 43 & 36 & $3 / 7$ & Pos & WEDGE & LLL & Thoracotomy & No & No & No & Yes & 2.1 & Lung & Yes & 213 & No \\
\hline$\# 12$ & Female, 71 & 306 & $2 / 4$ & Pos & WEDGE & RLL & Thoracotomy & $\begin{array}{l}\text { Yes, } 3 \\
\text { days }\end{array}$ & No & $\begin{array}{l}\text { Yes, acute renal } \\
\text { failure }\end{array}$ & No & NA & NA & NA & 19 & No \\
\hline$\# 13$ & Male, 62 & 62 & $1 / 12$ & Neg & SEGMENTECTOMY & RLL & VATS & No & Yes & Yes, haemothorax & No & NA & NA & NA & 8 & No \\
\hline \#14 & Male, 68 & 42 & 1/17 & Neg & WEDGE & LLL & VATS & No & No & No & Yes & 1.5 & Multifocal & No & 47 & No \\
\hline$\# 15$ & Male, 64 & 1 & 1/10 & NA & WEDGE & LUL & VATS & No & No & No & Yes & 23.7 & Multifocal & No & 33 & Yes \\
\hline$\# 16$ & Male, 68 & 8 & $1 / 13$ & NA & WEDGE & RLL & VATS & No & No & No & No & NA & NA & NA & 32 & No \\
\hline \#17 & Male, 49 & 6 & 2/12 & NA & WEDGE & RLL & VATS & No & No & No & No & NA & NA & NA & 32 & No \\
\hline \#18 & Male, 51 & 51 & $1 / 33$ & Pos & WEDGE & ML & Thoracotomy & No & No & No & Yes & 14.5 & Multifocal & No & 21 & Yes \\
\hline$\# 19$ & Male, 68 & 36 & 2/15 & Pos & WEDGE & LLL, LUL & Thoracotomy & No & No & No & Yes & 15 & Lung & No & 51 & Yes \\
\hline \#20 & Male, 70 & 67 & $1 / 14$ & Neg & LOBECTOMY & ML & VATS & No & No & No & Yes & 5.3 & Liver & No & 57 & No \\
\hline \#21 & Male, 56 & 50 & $1 / 6$ & Neg & WEDGE & RLL & VATS & No & No & No & No & NA & NA & NA & 36 & No \\
\hline \#22 & Male, 52 & 14 & $1 / 22$ & Pos & WEDGE & RLL & Thoracotomy & No & No & No & Yes & 32.6 & Lung & Yes & 35 & No \\
\hline \#23 & Male, 53 & 20 & 1/13 & Pos & WEDGE & RLL & Thoracotomy & No & No & No & No & NA & NA & NA & 12 & No \\
\hline \#24 & Male, 58 & 46 & 3/15 & Neg & WEDGE & LLL & VATS & No & No & No & No & NA & NA & NA & 18 & No \\
\hline \#25 & Male, 73 & 121 & 2/15 & Pos & WEDGE & LLL. & Thoracotomy & No & No & No & No & NA & NA & NA & 6 & No \\
\hline
\end{tabular}

LLL, left lower lobe; LUL, left upper lobe; PET, positron emission tomography; LM, median lobe; RLL, right lower lobe; RUL, right upper lobe; ICU, intensive care unit

VATS, video-assisted thoracic surgery; MWA, percutaneous microwave ablation; " Diagnostic surgery; Pos, positive; Neg, negative; NA, not available or not applicable. 


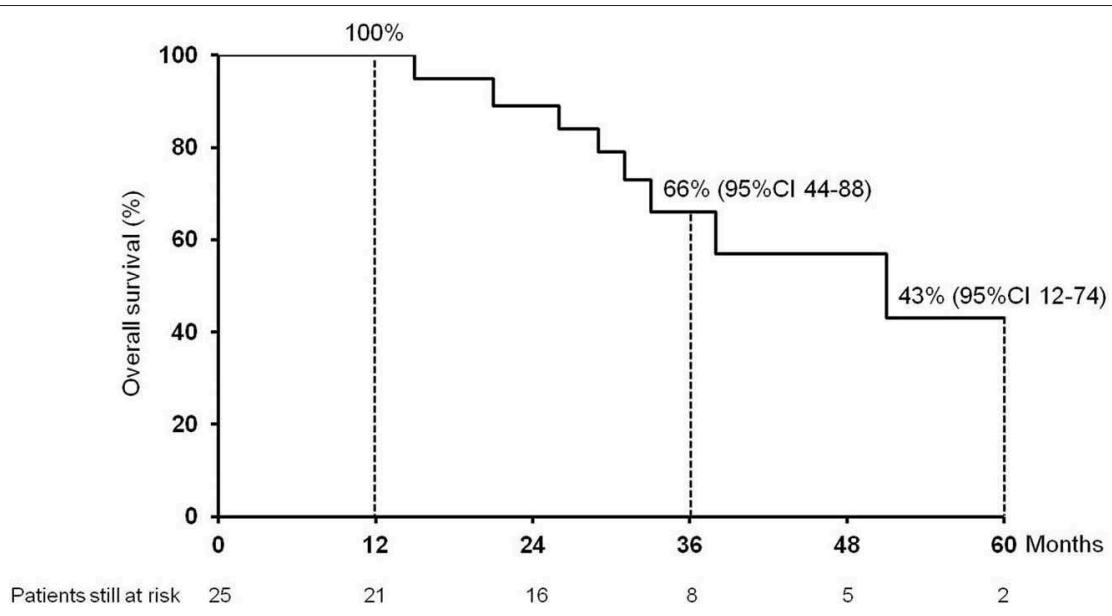

FIGURE 1 | Cumulative survival (1, 3, and 5 year) of the 25 patients enrolled in the study after hepatocellular carcinoma recurrence following liver transplantation.

\section{DISCUSSION}

This is the first study, to the best of our knowledge, to specifically evaluate the impact and management of lung metastases in HCC recurrence after LT. We observed a low occurrence of complications, no surgery-related mortality and a good feasibility of surgery in those patients judged operable after first RPM whenever HCC recurred in lung. We observed that the majority of recurrences were in the right lower lobe. This is probably due to the proximity of this site to the liver at the time of hepatectomy and to the lymphatic drainage. Finally, we detected good longterm survival outcomes, with a 1-, 3-, and 5 year cumulative probability of OS from recurrence of 100\%, 66\% (95\%CI 44-88) and $43 \%(95 \%$ CI $12-74)$, respectively, and a median OS of 51 months (95\%CI 24-78).

Our study would have a great impact in the setting of LT for HCC, since the second most common site of HCC recurrence is the lung. Whenever the lesions were limited to the lung, we were able to show that complete resection can be safely performed, which may have contributed to the long-term survival of these patients, while some reviews advocated more aggressive surgical intervention $(5,6)$. This is of great importance, since tumor recurrence would have obviously decreased the opportunity of long-term survival after LT for HCC $(6,15)$. To the best of our knowledge, only few reports of resection for pulmonary metastasis from HCC after liver transplantation are available $(15,16,18-22)$. In particular, Bates et al. (16) reported five cases of metastatic HCC resection after liver transplantation, with a survival period of 44 months after LT and 28 months after pulmonary resection.

Finally, our results in terms of OS are comparable to those of patients following metastasectomy after liver resection for HCC in patients without history of LT (14, 23-25).

Although prognostic indicators are not known, several clinical or pathological factors have been published $(14,23,26$, 27). Generally, patient selection and metastasis characteristics (such as number and side of lesions) are indispensable for a surgery survival benefit. In additional, good liver function might be essential for better survival $(28,29)$. As confirmation of this, in our study population was well-selected (only lung metastasis) with a good liver function (no patients with decompensated disease).

After the metastasectomy, recurrence may be managed by a repeated metastasectomy $(23,30-32)$. In our series, 4 patients ( 3 cases for recurrence, once case to complete the resection) underwent to a second pulmonary resection for a recurrent PMHCC after a metastasectomy. Multiple metastases or repeated metastasectomies are not risk factors for long-term survival, as shown in this and previous studies $(31,33)$, although patients with a single metastasis or single pulmonary surgery might show better survival $(23,26)$.

Limitations of our study are: the retrospective design, the lack of a control arm and the limited number of patients. The impact of surgical access on outcome cannot be assessed, due to the limited number of patients. However, the study has several strengths: this is the largest consecutive series of patients affected by lung HCC-metastasis treated surgery in the post-transplant setting. Moreover, despite the retrospective design of the study, the cohort is homogeneous regarding the baseline features and the patient management.

In conclusion, selected patients without intrahepatic HCCrecurrence after LT and with preserved hepatic function showed that a pulmonary metastasectomy could be efficacious in managing a PM-HCC and could give an opportunity for longterm survival.

\section{DATA AVAILABILITY STATEMENT}

The datasets generated for this study are available on request to the corresponding author.

\section{ETHICS STATEMENT}

Ethical approval was not provided for this study on human participants because this is a retrospective. The patients/participants provided their written informed consent to participate in this study. 


\section{AUTHOR CONTRIBUTIONS}

FI, MI, and PM planned the study, analyzed and interpreted the data, and wrote the manuscript. MN and UC participated in

\section{REFERENCES}

1. Bruix J, Sherman M. American association for the study of liver diseases. Management of hepatocellular carcinoma: an update. Hepatology. (2011) 53:1020-2. doi: 10.1002/hep.24199

2. European Association for the Study of the Liver. EASL clinical practice guidelines: management of hepatocellular carcinoma. J Hepatol. (2018) 69:182-236. doi: 10.1016/j.jhep.2018.03.019

3. Mazzaferro V, Regalia E, Doci R, Andreola S, Pulvirenti A, Bozzetti F, et al. Liver transplantation for the treatment of small hepatocellular carcinomas in patients with cirrhosis. $N$ Engl J Med. (1996) 334:693-9. doi: 10.1056/NEJM1996031433 41104

4. Duvoux C, Roudot-Thoraval F, Decaens T, Pessione F, Badran H, Piardi T, et al. Liver Transplantation French Study Group. Liver transplantation for hepatocellular carcinoma: a model including $\alpha$-fetoprotein improves the performance of Milan criteria. Gastroenterology. (2012) 143:986-94. doi: 10.1053/j.gastro.2012. 05.052

5. Roayaie S, Schwartz JD, Sung MW, Emre SH, Miller CM, Gondolesi GE, et al. Recurrence of hepatocellular carcinoma after liver transplant: patterns and prognosis. Liver Transpl. (2004) 10:534-40. doi: 10.1002/lt. 20128

6. Regalia E, Fassati LR, Valente U, Pulvirenti A, Damilano I, Dardano $\mathrm{G}$, et al. Pattern and management of recurrent hepatocellular carcinoma after liver transplantation. J Hepatobiliary Pancreat Surg. (1998) 5:29-34. doi: 10.1007/PL00009947

7. Davis E, Wiesner R, Valdecasas J, Kita Y, Rossi M, Schwartz M. Treatment of recurrent hepatocellular carcinoma after liver transplantation. Liver Transpl. (2011) 17:S162-6. doi: 10.1002/lt.22361

8. Welker MW, Bechstein WO, Zeuzem S, Trojan J. Recurrent hepatocellular carcinoma after liver transplantation - an emerging clinical challenge. Transpl Int. (2012) 26:109-18. doi: 10.1111/j.1432-2277.2012.0 1562.x

9. Sposito C, Mariani L, Germini A, Flores Reyes M, Bongini M, Grossi $G$, et al. Comparative efficacy of sorafenib versus best supportive care in recurrent hepatocellular carcinoma after liver transplantation: a case-control study. J Hepatol. (2013) 59:59-66. doi: 10.1016/j.jhep.2013. 02.026

10. Clavien PA, Lesurtel M, Bossuyt PM, Gores GJ, Langer B, Perrier A. Recommendations for liver transplantation for hepatocellular carcinoma: an international consensus conference report. Lancet Oncol. (2012) 13:e11-22. doi: 10.1016/S1470-2045(11)70175-9

11. Alshahrani AA, Ha SM, Hwang S, Ahn CS, Kim KH, Moon DB, et al. Clinical features and surveillance of very late hepatocellular carcinoma recurrence after liver transplantation. Ann Transplant. (2018) 23:659-65. doi: 10.12659/AOT.910598

12. Chok KS, Chan SC, Cheung TT, Chan AC, Fan ST, Lo CM. Late recurrence of hepatocellular carcinoma after liver transplantation. World J Surg. (2011) 35:2058-62. doi: 10.1007/s00268-0111146-Z

13. Foerster F, Hoppe-Lotichius M, Vollmar J, Marquardt JU, Weinmann A, Wörns MA, et al. Long-term observation of hepatocellular carcinoma recurrence after liver transplantation at a European transplantation centre. United European Gastroenterol J. (2019) 7:838-49. doi: 10.1177/2050640619840221

14. Tomimaru Y, Sasaki Y, Yamada T, Eguchi H, Takami K, Ohigashi $\mathrm{H}$, et al. The significance of surgical resection for pulmonary metastasis from hepatocellular carcinoma. Am J Surg. (2006) 192:46-51. doi: 10.1016/j.amjsurg.2005.12.006 the analyzing of data and writing of the manuscript. $\mathrm{CZ}, \mathrm{MD}$, $\mathrm{MN}, \mathrm{PL}$, and LD critically revised the manuscript for important intellectual content. FI, MI, AM, MT, SC, AR, CZ, MS, GC, FR, $\mathrm{RB}, \mathrm{DD}$, and PM enrolled patients and acquired data.

15. Kornberg A, Küpper B, Tannapfel A, Katenkamp K, Thrum K, Habrecht $\mathrm{O}$, et al. Long-term survival after recurrent hepatocellular carcinoma in liver transplant patients: clinical patterns and outcome variables. Eur J Surg Oncol. (2010) 36:275-80. doi: 10.1016/j.ejso.2009. 10.001

16. Bates MJ, Farkas E, Taylor D, McFadden PM. Pulmonary resection of metastatic hepatocellular carcinoma after liver transplantation. Ann Thorac Surg. (2008) 85:412-5. doi: 10.1016/j.athoracsur.2007. 10.065

17. Lencioni R, Llovet JM. Modified RECIST (mRECIST) assessment for hepatocellular carcinoma. Semin Liver Dis. (2010) 30:52-60. doi: 10.1055/s-0030-1247132

18. Bazan HA, McMurtry KA, Waters PF, Thung SN. Surgical resection of pulmonary metastases after orthotopic liver transplantation for hepatocellular carcinoma. Transplantation. (2002) 73:1007-8. doi: 10.1097/00007890-200203270-00034

19. Viola C, Asselah T, Samuel D, Durand F, Boudjema H, Valla D, et al. Solitary pulmonary metastasis arising thirteen years after liver transplantation for HBV-related hepatocellular carcinoma. World J Gastroenterol. (2006) 12:4911-3. doi: 10.3748/wjg.v12.i30.4911

20. Zhang C, Rao J, Tu Z, Ni Y. Surgical resection of resectable thoracic metastatic hepatocellular carcinoma after liver transplantation. J Thorac Cardiovasc Surg. (2009) 138:240-1. doi: 10.1016/j.jtcvs.2008. 05.014

21. Asaoka T, Marubashi S, Dono K, Hama N, Kim C, Kobayashi S, et al. Management of pulmonary recurrence of hepatocellular carcinoma after receiving a living-donor liver transplantation - a case report (in Japanese). Jpn J Cancer Chemother. (2008) 35:2086-7.

22. Fernandez-Sevilla E, Allard MA, Selten J, Golse N, Vibert E, Sa Cunha A, et al. Recurrence of hepatocellular carcinoma after liver transplantation: Is there a place for resection? Liver Transpl. (2017) 23:440-7. doi: 10.1002/lt. 24742

23. Nakajima J, Tanaka M, Matsumoto J, Takeuchi E, Fukami T, Takamoto S. Appraisal of surgical treatment for pulmonary metastasis from hepatocellular carcinoma. World J Surg. (2005) 29:715-8. doi: 10.1007/s00268-0057687-2

24. Nakamura T, Kimura T, Umehara Y, Suzuki K, Okamoto K, Okumura T, et al. Long-term survival after report resection of pulmonary metastases from hepatocellular carcinoma: report of two cases. Surg Today. (2005) 35:890-2. doi: 10.1007/s00595-005-3022-7

25. Wang L, Ye G, Zhan C, Sun F, Lin Z, Jiang W, et al. Clinical factors predictive of a better prognosis of pulmonary metastasectomy for hepatocellular carcinoma. Ann Thorac Surg. (2019) 108:1685-91. doi: 10.1016/j.athoracsur.2019.06.086

26. Lam CM, Lo CM, Yuen WK, Liu CL, Fan ST. Prolonged survival in selected patients following surgical resection for pulmonary metastasis from hepatocellular carcinoma. $\mathrm{Br} J$ Surg. (1998) 85:1198-200. doi: 10.1046/j.1365-2168.1998.0 0846.

27. Natsuizaka M, Omura $T$, Akaike $T$, Kuwata $Y$, Yamazaki $K$, Sato $\mathrm{T}$, et al. Clinical features of hepatocellular carcinoma with extrahepatic metastases. J Gastroenterol Hepatol. (2005) 20:1781-7. doi: 10.1111/j.1440-1746.2005.03919.x

28. Schwartz M, Roayaie S, Llovet J. How should patients with hepatocellular carcinoma recurrence after liver transplantation be treated? J Hepatol. (2005) 43:584-9. doi: 10.1016/j.jhep.2005. 07.019

29. Arii S, Monden K, Niwano M, Furutani M, Mori A, Mizumoto $\mathrm{M}$, et al. Results of surgical treatment for recurrent hepatocellular carcinoma; comparison of outcome among patients with multicentric 
carcinogenesis, intrahepatic metastasis, and extrahepatic recurrence. J Hepatobiliary Pancreat Surg. (1998) 5:86-92. doi: 10.1007/PL000 09956

30. Poon RT, Fan ST, O’Suilleabhain CB, Wong J. Aggressive management of patients with extrahepatic and intrahepatic recurrences of hepatocellular carcinoma by combined resection and locoregional therapy. J Am Coll Surg. (2002) 195:311-8. doi: 10.1016/S1072-7515(02)0 1226-7

31. O'Suilleabhain CB, Poon RT, Lau CW, Fan ST. Repeated resections of extrahepatic metastases after hepatic resection: an aggressive approach to hepatocellular carcinoma. Hepatogastroenterology. (2004) 51:825-9.

32. Gwak GY, Jung JO, Sung SW, Lee HS. Long-term survival after pulmonary metastatectomy of hepatocellular carcinoma; treatment outcome or natural history? Hepatogastroenterology. (2004) 51:1428-33.

33. Koide N, Kondo H, Suzuki K, Asamura H, Shimada K, Tsuchiya R. Surgical treatment of pulmonary metastasis from hepatocellular carcinoma. Hepatogastroenterology. (2007) 54:152-6.
Conflict of Interest: FI is a member of a speakers bureau for Abbvie and Gilead Science. MI received speaking and teaching fees from Bayer, Gilead Science, Janssen, BTG, and Abbvie, and is a consultant for BTG. PL is a member of a speakers bureau for BMS, Roche, Gilead Sciences, GSK, MSD, and Abbvie, and is on an advisory board for Janssen, Eiger, and Myr pharma. MFD is a member of a speakers bureau for BMS, Abbvie, and MSD.

The remaining authors declare that the research was conducted in the absence of any commercial or financial relationships that could be construed as a potential conflict of interest.

Copyright (c) 2020 Invenizzi, Iavarone, Donato, Mazzucco, Torre, Conforti, Rimessi, Zavaglia, Schiavon, Comacchio, Rea, Boetto, Cillo, Dondossola, De Carlis, Lampertico, Nosotti and Mendogni. This is an open-access article distributed under the terms of the Creative Commons Attribution License (CC BY). The use, distribution or reproduction in other forums is permitted, provided the original author(s) and the copyright owner(s) are credited and that the original publication in this journal is cited, in accordance with accepted academic practice. No use, distribution or reproduction is permitted which does not comply with these terms. 